\title{
Pengelolaan Pariwisata Warisan Budaya Di Kawasan Istana Asserayah Al-Hasyimiah Kabupaten Siak - Provinsi Riau
}

\author{
Aisyah Astinadia Siregar \\ Magister Kajian Pariwisata, Universitas Gadjah Mada, Yogyakarta, Indonesia
}

aisyah.astinadia@mail.ugm.ac.id

\begin{abstract}
ABSTRAK
Istana Asserayah Al-Hasyimiah merupakan bangunan peninggalan Kesultanan Siak Sri Indrapura yang memiliki latar belakang sejarah kerajaan Melayu Islam terbesar di Riau. Namun dalam pengelolaan warisan budaya di kawasan Istana Asserayah AlHasyimiah saat ini belum berjalan optimal karena para pemangku kepentingan belum bersinergi dalam mendukung pengelolaan warisan budaya. Tujuan dari penelitian ini adalah untuk Menganalisis pengelolaan pariwisata warisan budaya di kawasan Istana Asserayah Al-Hasyimiah, mengidentifikasi partisipasi pemangku kepentingan dalam pengelolaan pariwisata warisan budaya, merumuskan model pengelolaan pengembangan pariwisata warisan budaya yang sesuai bagi pengelolaan kawasan Istana Asserayah Al-Hasyimiah. Jenis penelitian ini adalah kualitatif dengan menggunakan metode kualitatif deskriptif. Teknik pengambilan data dilakukan dengan cara observasi, wawancara mendalam, dokumentasi, focus group discussion (FGD). Metode analisis data menggunakan analisis etnografi untuk mengetahui dan mengidentifikasi jenis dan peran para pemangku kepentingan dalam pengelolaan warisan budaya. Hasil dari analisis etnografi, usulan strategi pengelolaan pariwisata warisan budaya yang sesuai adalah model kolaborasi antar pemangku kepentingan dengan mengimplementasikan kepentingan bersama melalui sebuah forum yaitu Forum Komunikasi Pariwisata Siak agar pengelolaan kawasan Istana Asserayah AlHasyimiah dapat berjalan dengan baik
\end{abstract}

ARTICLE HISTORY

Submitted:21.06.2021

Revised:22.06.2021

Accepted:08.07.2021

Online first:10.07.2021

\section{KEYWORDS}

Pengelolaan, Warisan Budaya, Istana 


\section{1. latar Belakang}

Indonesia merupakan negara kepulauan yang memiliki kekayaan alam, budaya, dan manusia sangat besar dan beragam yang merupakan sumber kepariwisataan. Dari potensi-potensi pariwisata yang ada, salah satu kekayaan bangsa Indonesia yang menjadi daya tarik adalah kekayaan warisan budaya. Warisan budaya adalah warisan peninggalan masa lalu yang diwariskan dari generasi yang satu kepada generasi yang lain, yang tetap dilestarikan, dilindungi, dihargai dan dijaga kepemilikannya (Ardika, 2007:19). Sumber daya budaya dibedakan menjadi dua yaitu yang bersifat fisik (tangible) dan non fisik (intangible) di mana keduanya merupakan kekaya yang tidak ternilai dan sekaligus merupakan cultural identity atau kepribadian budaya bangsa (Atmosudiro dalam Hermawan, 2009:14).

Provinsi Riau adalah salah satu provinsi kaya akan sumber daya alamnya. Provinsi ini terletak di bagian tengah Pantai Timur Pulau Sumatera yaitu sepanjang pesisir Selat Malaka, serta provinsi ini juga berhadapan dengan dua negara maju yaitu Malaysia dan Singapura. Kabupaten Siak merupakan salah satu kabupaten yang ada di Provinsi Riau. Kabupaten ini terkenal dengan slogan "Siak The Trully Malay" artinya melayu yang sebenarnya ada di Kabupaten Siak.

Salah satu obyek wisata yang dikembangkan sebagai warisan budaya adalah Istana Asserayah Al-Hasyimiah dan warisan lain yang berada di sekitarnya. Istana Asserayah Al-Hasyimiah sudah masuk ke dalam cagar budaya yang dilindungi, bangunan ini dikelola oleh Dinas Pariwisata Kabupaten Siak. Hal ini menyebabkan pemanfaatan kawasan Istana Asserayah Al-Hasyimiah dan sekitarnya selama ini masih terkonsentrasi hanya di area Istana Asserayah Al-Hasyimiah saja, sementara warisan- warisan yang berada di sekitarnya belum terkelola dengan optimal. Kawasan Istana Asserayah Al-Hasyimiah termasuk dalam Kawasan strategis pariwisata nasional. Kawasan Istana Asserayah Al-Hasyimiah juga ditetapkan sebagai kawasan strategis nasional pelestarian sosial budaya, sedangkan kawasan di sekitarnya yang terdapat bangunan bersejarah sebagai kawasan strategis provinsi. Ada tujuh lokasi sebaran warisan budaya terutama yang ada di Kawasan Istana Asserayah Al-Hasyimiah yaitu Makam Koto Tinggi, Balai Kerapatan Tinggi, Jembatan Siak, Klenteng Hock Siu Kong, Gudang Mesiu, Makam Sultan Syarif Qasim II, dan Masjid Syahabuddin. Namun, tingkat kunjungan wisatawan dan lama tinggal masih rendah. Padahal warisan budaya tak benda ini merupakan potensi pendukung atraksi wisata, apabila dikemas lebih baik lagi agar diminati oleh wisatawan.

Berdasarkan fakta di lapangan dapat diketahui bahwa sebenarnya potensi warisan budaya yang ada di Kawasan Istana Asserayah Al-Hasyimiah dan sekitarnya sangat besar, namun karena pengelolaannya belum melibatkan masyarakat setempat secara langsung dan adanya tumpang tindih kebijakan sehingga belum memberikan manfaat yang langsung dirasakan oleh masyarakat sekitar, sehingga dibutuhkan pengeloaan yang tepat mengenai kawasan Istana Asserayah Al-Hasyimiah agar tidak menjadi simpang siur. 


\section{Kajian Pustaka}

Menurut Ardhan et al (2014), penetapan sistem zonasi terdiri dari Zona Inti, Zona Penyangga dan Zona Pendukung. Jika dilihat dari posisi dan juga pengaruhnya, stakeholder dapat dibedakan menjadi tiga kelompok menurut Maryono, et al (2005) dalam penelitian Yosevita (2015) yang meliputi Stakeholder Primer, Stakeholder Sekunder dan Key Stakeholeder. Berdasarkan Pentahelix, kontribusi dari pemangku kepentingan terdiri dari lima komponen yaitu antara lain Akademisi, Bisnis, Komunitas, Pemerintah, dan Media. Fungsi manajemen untuk pengembangan dan pemanfaatan kawasan tersebut tentunya tidak lepas dari Perencanaan, Pengorganisasian, Pelaksanaan, dan Pengawasan.

\section{Metode Penelitian}

Penelitian ini merupakan penelitian deskriptif dengan pendekatan kualitatif. Objek penelitian ini berfokus pada kawasan Istana Asserayah AlHasyimiah. Data primer didapatkan melalui metode observasi di lapangan, wawancara mendalam yang di lakukan bersama masing-masing pemangku kepentingan dengan teknik snowball purposive sampling, dan FGD untuk menyatukan gagasan dari masing-masing pemangku kepentingan. Sedangkan data primer diperoleh dari studi pustaka untuk memperoleh data yang akurat serta dokumentasi. Data yang didapatkan lalu diolah menggunakan analisis Etnografi terdiri dari analisis domain, taksonomik, komponensial dan tema. Hasil dari analisis tersebut, partisipasi peran pemangku kepentingan menjadi dasar formulasi manajemen membuat model pengelolaan pariwisata warisan budaya di kawasan Istana Asserayah Al-Hasyimiah.

\section{Hasil dan Pembahasan}

a. Pengelolaan Pariwisata Warisan Budaya Di Kawasan Istana Asserayah AlHasyimiah

1. Pembagian Zona Pengelolaan

Peraturan zonasi terdiri dalam teks zonasi dan peta zonasi sesuai dengan Pasal 157 ayat 1 Peraturan Pemerintah No. 15 Tahun 2010. Menurut Pasal 73 Undang - Undang No. 11 Tahun 2010 tentang Cagar Budaya, penetapan sistem zonasi terdiri dari Zona 1 atau Zona Inti, Zona 2 atau Zona Pendukung, Zona 3 atau Zona Penyangga.

a. Zona Inti Warisan Budaya di Kabupaten Siak

- Etnografi Zona Inti Kompleks Kerajaan Siak

Berdasarkan dari sejarah dan letak sebaran warisan budaya yang berdekatan, serta pengamatan selama di lapangan bersama pemangku kepentingan zona inti khusus terdiri atas Istana Asserayah Al Hasyimiah, Balai Kerapatan Tinggi, Makam Sultan Syarif Kasim II, 
Masjid Raya Syahabuddin (Kelompok Barat) dan Jembatan Istana, Makam Koto Tinggi, dan Gudang Mesiu (Kelompok Timur).

- Etnografi Zona Inti Kelenteng Hock Siu Kong

Berdasarkan sejarah dan letak warisan budaya, pengamatan dilapangan bersama pemangku kepentingan zona inti Kelenteng Hock Siu Kong terletak pada satu blok saja.

b. Zona Pendukung Warisan Budaya di Kabupaten Siak

- Etnografi Zona Pendukung Kompleks Kerajaan Siak

Adapun kawasan zona pendukung Kompleks dari Kerajaan Siak terbagi menjadi 3 kelompok yaitu : kompleks pemukiman masyarakat melayu yang bernama gajah minum (Kelompok Barat), kawasan komersil yaitu pasar kesenian yang menjual berbagai souvenir atau oleh-oleh khas Siak (Kelompok Timur), dan pemukimam Kerabat Kerajaan (Kelompok Utara).

- Etnografi Zona Pendukung Kelenteng Hock Siu Kong

Zona pendukung Kelenteng Hok Sing Kong ini merupakan kawasan

Pecinan yang merupakan pasar lama yang menjadi pusat pertokoan yang menjual pernak pernik untuk perayaan hari besar masyarakat Tionghoa seperti lampion, kue bulan, manisan Cina dan peralatan upacara lainnya.

c. Zona Penyangga Warisan Budaya di Kabupaten Siak

- Etnografi Zona Penyangga Kompleks Kerajaan Siak

Zona penyangga Kompleks Kerajaan Siak ini terletak di kawasan permukiman jenis atau aktivitas masyarakat dimana pada zona ini tedapat kegiatan indusri kerajinan, taman suak santai sebagai ruang terbuka.

- Etnografi Zona Penyangga Kelenteng Hock Siu Kong

Zona ini memiliki jenis atau kegiatan masyarakat yaitu kegiatan berdagang pada kawasan ini juga terdapat pemakaman etnis tionghoa yang menandakan kawasan ini didominasi oleh etnis Tionghoa.

2. Pengelolaan Kawasan Istana Asserayah Al Hasyimiah

Adapun pengelolaan kawasan yang dapat dilakukan yaitu meningkatkan potensi nilai warisan budaya, pengelolaan lingkungan kawasan pariwisata warisan budaya, dukungan sosial dari masyarakat setempat dan adanya partisipasi dari pemangku kepentingan.

3. Masalah dan Solusi Pengelolaan Kawasan Istana Asserayah Al-Hasyimiah

a. Masalah Pengelola dengan Warga Sekitar

Adapun masalah yang dihadapi pengelola dengan warga sekitar yaitu penguasaan tanah di situs Istana Asserayah Al-Hasyimiah, masyarakat belum dilibatkan dalam pengelolaan, warga tidak mendapatkan dispensasi tiket masuk, dan ada beberapa situs yang tidak buka setiap hari. 
b. Permasalahan Antar Pengelola

Permasalahan antar pengelola seperti pengelola berasal dari Instansi dan kepentingan berbeda, lemahnya koordinasi di tingkat lapangan, Dinas Pariwisata belum melibatkan pemangku kepentingan lain, dan terjadi ketidakseimbangan antara pelestarian dan pemanfaatan.

b. Partisipasi Pemangku Kepentingan Dalam Pengelolaan Pariwisata Warisan Budaya Di Kawasan Istana Asserayah Al-Hasyimiah

1. Pemangku Kepentingan dalam Pengelolaan Pariwisata Warisan Budaya di Kawasan Istana Asserayah Al-Hasyimiah

\section{a. Dinas Pariwisata Siak}

Tugasnya adalah melaksanakan urusan pemerintah daerah berdasarkan asas otonomi dan tugas pembantuan di Bidang Pariwisata. Adapun fungsinya yaitu perumusan kebijakan teknis di bidang pariwisata, penyelenggaraan pelayanaan umum di bidang pariwisata, pembinaan pelaksanaan tugas di bidang pariwisata, pelaksanaan urusan tata usaha dinas, dan pelaksanaan tugas lain yang diberikan oleh Bupati sesuai dengan tugas dan fungsinya.

\section{b. Dinas Pendidikan dan Kebudayaan Kabupaten Siak}

Bagian seksi cagar budaya dan permuseuman melaksanakan tugas yaitu Penyusunan bahan perumusan, koordinasi pelaksanaan kebijakan registrasi cagar budaya dan pelestarian cagar budaya, serta permuseuman; Penyusunan bahan pembinaan dan fasilitasi registrasi cagar budaya dan pelestarian cagar budaya; Penyusunan bahan pelaksanaan pelindungan, pengembangan, dan pemanfaatan museum; Penyusunan bahan penerbitan izin membawa cagar budaya ke luar daerah kabupaten/kota; Penyusunan bahan pemantauan dan evaluasi di bidang registrasi cagar budaya dan pelestarian cagar budaya, serta permuseuman; Pelaporan di bidang registrasi cagar budaya dan pelestarian cagar budaya, serta permuseuman; dan Melaksanakan tugas lain yang diberikan atasan sesuai tugas.

\section{c. Balai Pelestarian Cagar Budaya (BPCB) Sumatera Barat}

Didalam Balai Pelestarian Cagar Budaya Sumatera Barat terdapat daftar cagar budaya tidak bergerak dalam lingkup wilayah kerja yakni Provinsi Sumatera Barat, Riau dan Kepulauan Riau. Dari daftar pemutakhiran data cagar budaya Kabupaten Siak terdapat 8 cagar budaya yang berada di sekitar kawasan Istana Asserayah Al-Hasyimiah yaitu Istana Asserayah Al-Hasyimiah, Balai Kerapatan Tinggi, Makam Sultan Syarif Kasim II, Masjid Sultan, Makam Koto Tinggi, Jembatan Istana, Gudang Mesiu dan Kelenteng Hock Siu Kong. 


\section{d. Badan Perencanaan Pembangunan Daerah (Bappeda) Kabupaten Siak}

Adapun tugas Subbidang Pariwisata yaitu Penyusunan rencana kerja Subbidang Pariwisata, Tenaga Kerja, dan Kependudukan; Perumusan kebijakan teknis perencanaan urusan pariwisata, tenaga kerja, transmigrasi, dan kependudukan dan pencatatan sipil yaitu; Pengoordinasian, pelaksanaan, dan pembinaan perencanaan urusan pariwisata, tenaga kerja, transmigrasi, dan kependudukan dan pencatatan sipil; dan evaluasi dan penyusunan laporan pelaksanaan kerja Subbidang Pariwisata, Tenaga Kerja, dan Kependudukan.

e. Dinas Pekerjaan Umum, Tata ruang, Perumahan Rakyat dan Kawasan Permukiman Kabupaten Siak

Adapun tugas pokok dari Dinas Pekerjaan Umum adalah membantu Bupati dalam melaksanakan kewenangan daerah di bidang pekerjaan umum, pengembangan wilayah, permukiman, tata ruang, pertamanan, dan kebersihan.

\section{f. Lembaga Pendidikan}

Warisan budaya memiliki nilai pendidikan dan nilai ilmu pengetahuan, sehingga dari peninggalan warisan budaya ini dapat dijadikan bahan edukasi kepada pelajar. Selama ini kawasan Istana Asserayah AlHasyimiah menjadi salah satu tujan study tour mulai dari sekolahan, universitas hingga instansi. Adapun lembaga pendidikan yang turut andil dalam pengelolaan pariwisata warisan budaya di kawasan Istana Asserayah Al-Hasyimiah sebagai pemangku kepentingan seperti Universitas Riau (UNRI), Universitas Islam Negeri Sultan Syarif Qasim (UIN SUSKA RIAU), Universitas Islam Riau (UIR), dan Universitas Lancang Kuning (UNILAK).

\section{g. Penggiat Budaya}

Penggiat adalah orang yang membangkitkan semangat kebudayaan yang ada di daerah. Penggiat Budaya adalah orang yang ditugaskan Direktorat Jenderal Kebudayaan di daerah yaitu Membantu pemerintah dalam upaya menyebarluaskan akses informasi mengenai kebudayaan; Membantu pemerintah melakukan konsolidasi dengan masyarakat bidang kebudayaan; Membantu pemerintah dalam upaya mengumpulkan datadata kebudayaan; Melakukan pendampingan Program Desa Pemajuan Kebudayaan; Melakukan pendampingan terhadap Komunitas Budaya dan masyarakat di kabupaten atau kota dalam upaya perlindungan, pengembangan, dan pemanfatan.

\section{h. Asosiasi Usaha Pariwisata}

Adapun asosiasi usaha pariwisata yang terlibat dalam pengelolaan kawasan Istana Asserayah Al-Hasyimiah yaitu Asosiasi Perusahaan 
Perjalanan Indonesia (ASITA), Masyarakat Sadar Wisata (MASATA), Asosiasi Perusahaan Penjual Tiket Penerbangan Indonesia (ASTINDO), Perkumpulan Penyelenggara Jasaboga Indonesia (PPJI) dan Generasi Pesona Indonesia (GENPI) Riau.

\section{i. Media}

Lembaga Penyiaran Publik Lokal (LPPL) Kabupaten Siak salah satunya yaitu Siak Televisi. Lembaga disini berperan untuk mempromosikan pariwisata yang ada di Kabupaten Siak. Adapun kegiatan setiap weekendnya adalah mengeksplore tempat wisata agar makin banyak yang mengunjunginya. Kegiatan ini dinamakan Siak City yaitu mulai dari wisata sejarah, wisata budaya, wisata bahari, agrowisata hingga wisata kuliner.

\section{j. Masyarakat Setempat}

Masyarakat tempat disini adalah masyarakat yang tinggal berada tidak jauh dari kawasan Istana Asserayah Al-Hasyimiah. Mereka yang mengetahui aktivitas keseharian pariwisata yang terpusat di kawasan tersebut. Kawasan Istana Asserayah Al-Hasyimiah berada diantara dua desa yaitu Kelurahan Desa Kampung Rempak dan Desa Suak Lanjut.

2. Keterlibatan Pemangku Kepentingan dalam Pengelolaan Pariwisata Warisan Budaya di Kawasan Istana Asserayah Al-Hasyimiah

Pengelolaan disini dapat diartikan sebagai penataan, pemeliharaan, dan pemanfaatan sumber daya pariwisata.

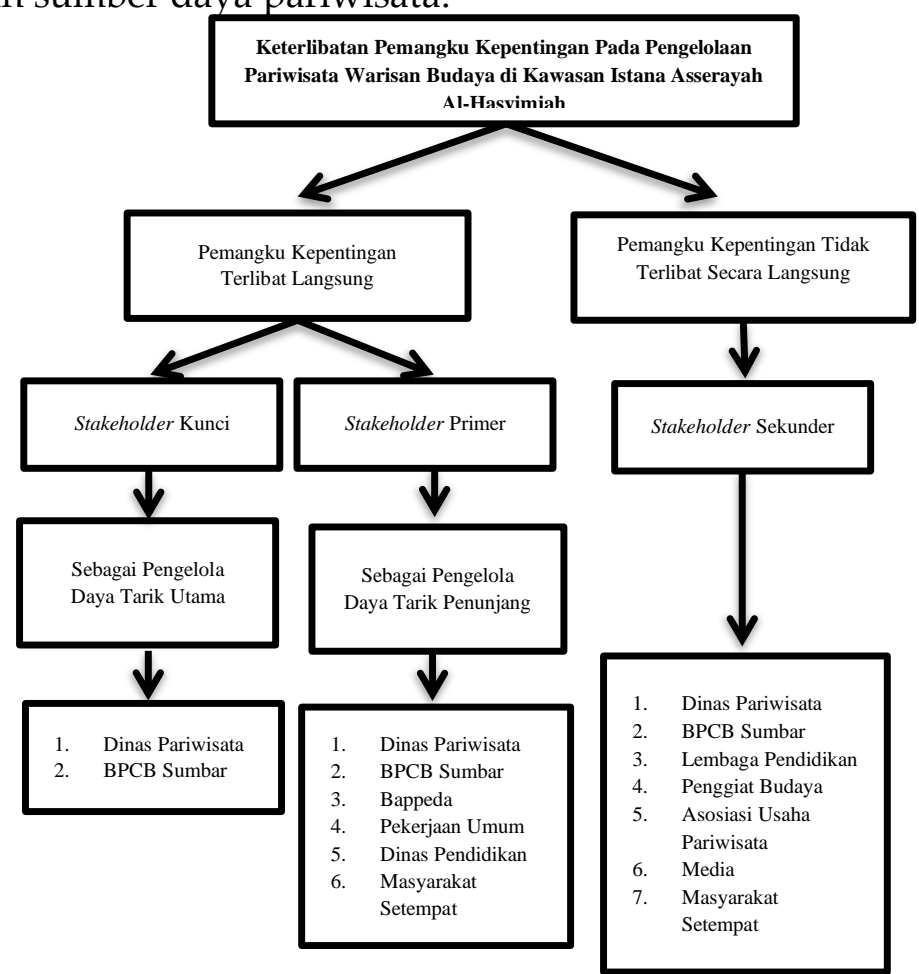

Gambar 1. Keterlibatan Stakeholder

(Sumber : Diolah peneliti, 2021) 
a. Pemangku kepentingan yang terlibat langsung dalam pengelolaan

1. Stakeholder kunci yaitu sebagai pengelola daya tarik utama yang terdiri dari Dinas Pariwisata meliputi area Zona Inti dan sebagian Zona Pendukung. Sedangkan BPCB Sumatera Barat pengelola di Zona Inti dan secara sistem di Zona Pendukung dan Penyangga.

2. Stakeholder Primer yaitu sebagai pengelola daya tarik penunjang dan kawasan yang terdiri dari Dinas Pariwisata Kabupaten Siak, Balai Pelestarian Cagar Budaya (BPCB) Sumatera Barat, Pemerintah Daerah melalui Bappeda dan Dinas Pekerjaan Umum (PU) Kabupaten Siak sebagai penyusun Regulasi yang berkaitan dengan perencanan wilayah yang mencakup Zona Inti, Zona Pendukung, Zona Penyangga. Lalu, Dinas Pendidikan dan Kebudayan Kabupaten Siak sebagai pembina kebudayaan yang berada di Zona Pendukung dan Zona Penyangga.

b. Pemangku kepentingan yang tidak terlibat secara langsung

Stakeholder Sekunder yaitu pemangku kepentingan secara tidak langsung terdiri dari Dinas Pariwisata Kabupaten Siak, Balai Pelestarian Cagar Budaya (BPCB) Sumatera Barat, Lembaga Pendidikan, Asosiasi Usaha Pariwisata, Penggiat Budaya, Media, dan Masyarakat setempat.

\section{c. Partisipasi Pemangku Kepentingan di KawasanWarisna Budaya}

1. Partisipasi Pemangku Kepentingan Dalam Perencanaan (Planning)

Dalam sebuah manajemen tentunya harus memiliki perencanaan (Planning) sebagai salah satu langkah basic dalam memulai sesuatu.. Perencanaan dilakukan untuk mencapai goals yang diinginkan. Adapun pemangku kepentingan yang berkecimpung di bagian perencanaan kawasan Istana Asserayah Al-Hasyimiah yaitu Dinas Pariwisata Kabupaten Siak, Dinas Pendidikan dan Kebudayaan Kabupaten Siak, Balai Pelestarian Cagar Budaya (BPCB) Sumatera Barat, Dinas Pekerja Umum (PU) dan Badan Perencanaan Pembangunan Daerah (Bappeda).

2. Partisipasi Pemangku Kepentingan Dalam Pengorganisasian (Organizing)

Setelah dari perencanaan maka langkah selanjutnya yaitu menggerakkan keseluruhan sumber mulai dari sumber daya manusia, tugas-tugas, wewenang-wewenang, hingga tanggung jawab yang telah direncanakan di awal. Dalam pengelolaan pariwisata warisan budaya di kawasan Istana Asserayah Al-Hasyimiah teridentifikasi pemangku kepentingan dalam pengorganisasian (Organizing) yaitu Dinas Pariwisata Kabupaten Siak, Dinas Pendidikan dan Kebudayaan Kabupaten Siak dan Balai Pelestarian Cagar Budaya (BPCB) Sumatera Barat.

3. Partisipasi Pemangku Kepentingan Dalam Pelaksanaan (Actuating) 
Pelaksanaan (Actuating) adalah proses dari setelah pengorganisasian dengan menggerakkan orang yang mau bekerja sama demi tercapainya tujuan yang telah ditentukan. Adapun pemangku kepentingan yang melaksanakan pelaksanaan pengelolaan yaitu Dinas Pariwisata Kabupaten Siak, Dinas Pendidikan dan Kebudayaan Kabupaten Siak dan Balai Pelestarian Cagar Budaya (BPCB) Sumatera Barat sebagai pengelola pariwisata warisan budaya di kawasan Istana Asserayah Al-Hasyimiah.

4. Partisipasi Pemangku Kepentingan Dalam Pengawasan (Controlling)

Pengawasan (controlling) yaitu proses pengamatan dari hasil tugas dengan penggunaan sumber-sumber tersebut dijalankan sesuai dengan rencana yang telah ditetapkan. Dalam pengelolaan pariwisata warisan budaya di kawasan Istana Asserayah Al-Hasyimiah yang melaksanakan pengawasan yaitu Dinas Pariwisata Kabupaten Siak dan Dinas Pendidikan dan Kebudayaan Kabupaten Siak.

\section{d. Promosi Yang Dilakukan Oleh Pemangku Kepentingan}

Hal yang dilakukan oleh pengelola dalam mempromosikan kawasan Istana Asserayah Al-Hasyimiah yaitu dengan pelaksanaan program pemasaran. Berbagai langkah sinergis dalam rangka pemasaran dan promosi bersama bagian pemasaran Dinas Pariwisata Kabupaten Siak yang telah dilakukan selama ini, seperti diskusi bersama pelaku-pelaku pariwisata serta kerja sama dengan Kementerian Pendidikan dan Kebudayan untuk memajukan nilai cagar budaya di kalangan banyak orang. Adapun pemangku kepentingan lain yang turut melakukan promosi dan merekomendasikan bahwa kawasan Istana Asserayah Al-Hasyimiah cocok untuk dikunjungi yaitu Asosiasi Usaha Pariwisata seperti ASITA, PHRI, HPI, GENPI dan sebagainya.

\section{e. Pemanfaatan Kawasan Oleh Pemangku Kepentingan}

Kawasan Istana Assserayah Al-Hasyimiah ini dikelola oleh Dinas Pariwisata Kabupaten Siak. Kawasan ini merupakan daya tarik utama Kabupaten Siak di Provinsi Riau. Sehingga menarik perhatian Bappeda untuk merencanakan memanfaatkan kawasan tersebut menjadikan objek perencanaan. Perencanaan yang dibuat diharapakan memberikan arahan pada kawasan Istana Asserayah AlHasyimiah menjadikan kawasan destinasi yang berkembang dengan baik. Setelah berkembang dan maju, kawasan Istana Asserayah Al-Hasyimiah dapat memberikan dampak terhadap Pendapatan Asli Daerah sebagai salah satu sumber APBD Kabupaten Siak. Dalam Asosiasi Usaha Pariwisata pengelolaannya hanya sebatas pada sisi pemanfaatan dan bentuk promosi. Mereka memafaatkan daya tarik wisata yang ada di kawasan ini sebagai produk yang akan mereka jual. Kemudian dari lembaga pendidikan memanfaatkan sebagai riset penelitiannya yang ke depannya dapat di manfaatkan instansi-instansi sebagai pedoman acuan pembuatan regulasi untuk perkembangan kawasan Istana Asserayah AlHasyimiah. Sementara dari masyarakat setempat sendiri manfaat yang bisa diambil adalah mengambil peluang dengan banyaknya kunjungan wisatawan 
dengan membuka kios-kios kecil di dekat kawasan yang menjual oleh-oleh khas Kabupaten Siak mulai dari kaos, gantungan kunci, sandal, pernak-pernik, hingga makanan khas Siak.

\section{f. Ketimpangan Partisipasi Pemangku Kepentingan Dalam Pengelolaan}

Keberadaan kawasan Istana Asserayah Al-Hasyimiah belum bisa berhasil sepenuhnya karena masyarakat belum dapat merasakan denyut nadi dari kegiatan pariwisata yang berimbas ke kehidupan mereka. Dari sejumlah keterlibatan pemangku kepentingan yang teridentifikasi, masih banyak fungsi manajemen yang belum merata. Hal itu menyebabkan munculnya berbagai ketidakseimbangan dalam kegiatan pengelolaan serta mempengaruhi tingkat kunjungan wisatawan dan lama tinggal di Kabupaten Siak, kurangnya variasi terhadap kunjungan obyek wisata.

g. Kolaborasi Antar Pemangku Kepentingan Sebagai Model Pengelolaan Pariwisata Warisan Budaya Di Kawasan Istana Asserayah Al-Hasyimiah

1. Kelemahan Dalam Pengelolaan Pariwisata Warisan Budaya di Kawasan Istana Asserayah Al-Hasyimiah

Masalah paling dominan dalam pengelolaan tersebut adalah kurangnya keterlibatan masing-masing pemangku kepentingan pada pengelolaan, karena dominasi oleh pengelola utama. Adapun bentuk permasalahan yang ada yaitu : penguasaan tanah di situs Istana Asserayah Al-Hasyimiah, belum ada kolaborasi antar objek warisan budaya, belum dilibatkan masyarakat sekitar atauppun pemangku kepentingan lainnya terhadap kegiatan pengelolaan di daerahnya, warga tidak mendapat dispensasi tiket masuk, situs warisan budaya ada yang tidak buka setiap hari, koordinasi di tingkat lapangan, sehingga terjadi ketidakseimbangan antara pelestarian dan pemanfaatan. Permasalahan-permasalahan tersebut membutuhkan strategi untuk bisa diselesaikan. Masing-masing pemangku bisa saling diskusi bersama untuk mencari solusi dari permasalahan yang ada di kawasan Istana Asserayah AlHasyimiah.

2. Pengembangan dalam Pengelolaan Pariwisata Warisan Budaya di Kawasan Istana Asserayah Al-Hasyimiah

Adapun pengembangan yang dapat dilakukan adalah mengikuti pelatihan sertifikasi kompetensi Sumber Daya Manusia (SDM), membuat variasi paket wisata, menyediakan shuttle antar objek, membuat Augmented Reality (AR)pada atraksi wisata, mengaplikasikan $Q R$ Code setiap zona, adanya penyewaan kostum unik setiap objek dan menghidupkan kembali pasar seni.

3. Model Pengelolaan Antar Pemangku Kepentingan untuk Pengelolaan Pariwisata Warisan Budaya di Kawasan Istana Asserayah Al-Hasyimiah

Adapun model pengelolaan yang sesuai dengan kondisi pariwisata warisan budaya di kawasan Istana Asserayah Al-Hasyimiah yaitu membentuk 
sebuah wadah yang bernama Forum Komunikasi Pariwisata Siak (FOKTAS). Forum ini akan di buat sistem websitenya agar semua bisa terkelola dengan baik. Sistem ini nantinya akan terdiri dari pemangku kepentingan seperti Dinas Pariwisata, Balai Pelestarian Cagar Budaya (BPCB) Sumbar, Dinas Pendidikan dan Kebudayaan, Dinas Pekerjaan Umum, Bappeda, Lembaga Pendidikan, Asosiasi Usaha Pariwisata, Penggiat Budaya, Media dan Masyarakat Setempat. Diharapkan di masa yang akan datang pengelolaan tidak terfokus pada Istana Asserayah Al-Hasyimiah saja, namun manfaat pengelolaan yang dirasakan juga menyebar ke seluruh kawasan.

Forum disini berfungsi tempat menyampaikan pandangan dan usulannya serta memantau kegiatan yang dilakukan oleh pengelola utama mulai dari perencanaan, pengorganisasian, pelaksanaan, dan pengawasan. Semua pemangku kepentingan yang terlibat memiliki kesempatan yang sama untuk berpartisipasi dalam menyampaikan ide dan gagasan. Oleh karena itu, pengelola utama akan selalu melibatkan semua pemangku kepentingan melalui Forum Komunikasi Pariwisata Siak (FOKTAS) ini ketika menjalankan semua fungsi manajemen dalam pengelolaan pariwisata warisna budaya di kawasan Istana Asserayah Al-Hasyimiah.

\section{Kesimpulan dan Saran}

Pengelolaan pariwisata warisan budaya di kawasan Istana Asserayah AlHasyimiah belum berjalan optimal, hal ini dikarenakan masyarakat belum dilibatkan secara langsung dan pengembangan hanya terbatas pada Istana Asserayah Al-Hasyimiah. Pemangku kepentingan yang terlibat dalam pengelolaan terdiri atas Pemangku Kepentingan Kunci (Dinas Pariwisata Kabupaten Siak dan Balai Pelestarian Cagar Budaya Sumatera Barat, dan Dinas Pendidikan dan Kebudayaan), Pemangku Kepentingan Primer (Dinas Pariwisata Kabupaten Siak, Balai Pelestarian Cagar Budaya Sumatera Barat, Bappeda, Dinas Pendidikan dan Kebudayaan, dan Dinas Pekerjaan Umum) dan Pemangku Kepentingan Sekunder (Lembaga Pendidikan, Asosiasi Usaha Pariwisata, Penggiat Budaya, Media, dan Masyarakat Setempat).

Terdapat 7 warisan budaya yang berada di sekitaran kawasan Istana Asserayah Al-Hasyimiah yaitu Balai Kerapatan Tinggi, Masjid Raya Syahabuddin, Makam Sultan Syarif Kasim II, Makam Koto Tinggi, Jembatan Istana, Gudang Mesiu dan Kelenteng Hock Siu Kong. Kawasan Istana Asserayah Al-Hasyimiah terbagi atas tiga zona yaitu zona inti, pendukung dan penyangga. masing-masing dari zona terbagi dua kawasan yaitu kawasan Kesultanan Kerajaan Siak dan Kelenteng Hock Siu Kong.

Pengembangan yang bisa dilakukan dalam pengelolaan pariwisata warisan budaya di kawasan Istana Asserayah Al-Hasyimiah yaitu pelatihan sertifikasi kompetensi Sumber Daya Manusia (SDM), membuat variasi paket wisata, 
menyediakan shuttle antar objek, membuat Augmented Reality (AR), mengaplikasikan $Q R$ Code, penyewaan kostum unik setiap objek dan menghidupkan kembali pasar seni. Membuat model pengelolaan yang tepat bersama pemangku kepentingan yaitu FOKTAS (Forum Komunikasi Pariwisata Siak).

Adapun harapan di masa yang akan datang dalam pengelolaan warisan budaya di Kawasan Istana Asserayah Al-Hasyimiah yaitu membuat regulasi tentang pengelola pariwisata warisan budaya, pihak pemerintah tetap memprioritaskan perlindungan dan pelestarian kawasan serta memberikan peluang bagi masyarakat setempat untuk mengembangkan daerahnya. Untuk lembaga pendidikan melakukan kajian yang terfokus dan mendalam mengenai pengelolaan warisan budaya Kabupaten Siak. Kepada Asosiasi Usaha Pariwisata agar dapat segera mengemas warisan budaya yang ada di kawasan Istana Asserayah Al-Hasyimiah agar menjadi beberapa opsi paket wisata yang menarik. Lalu bagi penggiat budaya dapat mendalami lagi upaya memngembangkan warisan budaya sesuai dengan potensi daerahnyaserta bagi media dapat mempromosikannya lebih luas lagi. 


\section{Author's declaration}

\section{Authors' contributions and responsibilities}

$\sqrt{ }$ The authors made substantial contributions to the conception and design of the study.

$\checkmark$ The authors took responsibility for data analysis, interpretation and discussion of results.

$\sqrt{ }$ The authors read and approved the final manuscript.

\section{Availability of data and materials}

$\sqrt{ }$ All data are available from the authors.

\section{Competing interests}

$\sqrt{ }$ The authors declare no competing interest. 


\section{Referensi}

1) Ardhan, Taufiq. 2014. Arahan Pengembangan Kota Palembang Sebagai Kota Pusaka. Surabaya : Institut Teknologi Sepuluh November.

2) Ardika, I.W. 2007. Pusaka Budaya \& Pariwisata. Denpasar: Penerbit Larasan.

3) Hermawan, Dody. 2009. Penilaian Ekonomi Cultural Heritage dengan Menggunakan Pendekatan Travel Cost Method. Yogyakarta: Universitas Gadjah Mada.

4) Peraturan Daerah Kabupaten Siak Nomor 2 Pasal 40 Tahun 2014 Tentang Rencana Tata Ruang Wilayah Kabupaten Siak 2019.

5) Rahardjo, S., dan Muluk, H. 2011. Pengelolaan Warisan Budaya di Indonesia. Bandung: CV Lubuk Agung.

6) Spradley, J.P. 1997. Metode Etnografi. Yogyakarta: Tiara Wacana.

7) Undang-undang Republik Indonesia Nomor 11 Tahun 2010 Tentang Cagar Budaya.

8) Yoeti, Oka A. 1997. Perencanaan dan Pengembangan Pariwisata. Jakarta: Pradnya Paramita.

9) Yosevita, L. 2015. Implementasi Peran Stakeholder Pengembangan Ekowisata di Taman Nasional Manusela (TNM) di Kabupaten Maluku Tengah. Jurnal Agroforestri, X(1), 21-30. 